the atrophy and dementia might possibly be precipitated prematurely by dopaminergic or anticholinergic drugs. Accumulated experience suggests that giving the maximum tolerated dosage of dopamine replacement may be injudicious until we can be more certain that this does not accelerate both dementia and brain atrophy.

Bromocriptine, a dopamine agonist, is an effective if expensive alternative treatment. ${ }^{8}$ Its side effects are, however, similar to those of levodopa. When bromocriptine is given with small doses of levodopa the combination seems able to prolong the total useful period of active treatment.

Where, then, do we stand ? For between one-third and a half of the clinical course of the disease many patients will benefit greatly from treatment with dopamine replacements or dopamine agonists. The start of such treatment should be delayed until the patient is beginning to find difficulty in coping with housework, shopping, or work. Probably the dosage should be kept as low as is consistent with achieving good functional improvement, particularly at the onset of treatment. Nevertheless, with all their limitations these drugs improve the quality of life and probably prolong survival to about 14 years from the onset of the disease.

${ }^{1}$ Hakim AM, Mathieson G. Dementia in Parkinson's disease: a neuropathologic study. Neurology 1979;29:1209-14.

2 Etienne P, Gauthier S, Johnson G, et al. Clinical effects of choline in Alzheimer's disease. Lancet 1978;i:508-9.

${ }^{3}$ Hoehn MM, Yahr MD. Parkinsonism: onset, progression, and mortality. Neurology (Minneap) 1967;17:427-42.

${ }^{4}$ Mjönes H. Paralysis agitans: a clinical and genetic study. Acta Psychiatrica et Neurologica Scandinavica 1949;54:1-195.

5 Pollock M, Hornabrook RW. The prevalence, natural history and dementia of Parkinson's disease. Brain 1966;89:429-48.

${ }^{6}$ Hunter KR, Shaw KM, Laurence DR, Stern GM. Sustained levodopa therapy in Parkinsonism. Lancet 1973;ii:929-31.

7 Shaw KM, Lees AJ, Stern GM. The impact of treatment with levodopa on Parkinson's disease. Q $\mathcal{F}$ Med 1980;49:283-93.

${ }^{8}$ Pearce JMS. Aetiology and natural history of Parkinson's disease. $\mathrm{Br} \mathrm{Med} \mathcal{F}$ 1978;ii:1664-6.

\section{Prostaglandins in obstetrics}

Prostaglandin preparations have now been used for over a decade for terminating pregnancy and for inducing labour, ${ }^{1}$ particularly when the cervix is unfavourable. ${ }^{2}{ }^{3}$ More recently pretreatment with prostaglandin has come into favour as a means of making suction termination of pregnancy less hazardous for nulliparous young women: the softening of the cervix makes dilatation easier and less traumatic.

Prostaglandins might have been given to more patients had they not had two disadvantages: a high incidence of distressing side effects and a relatively unpredictable action. In an attempt to overcome these problems many different routes of administration have been tried, including intra-amniotic, extraamniotic, intravenous, and oral and-less commonlyintramuscular injections, vaginal pessaries, and cervical gels.

The intra-amniotic route has proved excellent for the induction of midtrimester abortion. ${ }^{4}$ Slow absorption from the amniotic cavity keeps to a minimum the frequency and severity of side effects, but repeated doses of prostaglandin $E_{2}$ or $F_{2 \alpha}$ are often needed to achieve a success rate of $95 \%$. The 15-methyl analogues were developed in an attempt to improve the potency and prolong the duration of action of prostaglandins $E_{2}$ and $F_{2 \alpha}{ }^{5}$; these are resistant to degradation by the enzyme 15-hydroxy dehydrogenase. Clinical trials of 15-methyl prostaglandins using different routes have not always confirmed the initial expectations, ${ }^{67}$ but in 1973 Amy et $a l^{8}$ reported successful midtrimester termination of pregnancy in 18 out of 20 patients who were given a single $100 \mu \mathrm{g}$ dose of the 15-methyl $\mathrm{E}_{2}$ analogue by intra-amniotic injection. Side effects were minimal, but an attempt to reduce the induction-abortion interval from 16.5 hours by doubling the dose was unsuccessful. The increased dose also increases the risk of serious cardiovascular or respiratory side effects if the drug is absorbed unusually rapidly or accidentally injected intravenously.

The extra-amniotic routes of administration of prostaglandins were first described by Wiqvist and Bygdeman in $1970 .{ }^{9}$ Reports have shown some variation in the inductionabortion interval but it has generally been below 36 hours. The disadvantage of the need for repeated instillation of the drug through a transcervical catheter has been largely overcome by the introduction of continuous infusion systems. Concern that the presence of a catheter in the uterus would result in an increased risk of infection has generally been unfounded, but the possibility needs to be taken into account when choosing this method.

From the patients' standpoint the most convenient and acceptable preparation is a tablet. The many clinical trials ${ }^{10-12}$ of oral prostaglandins in inducing labour and terminating pregnancy have given consistent results. Labour can be induced successfully by this technique and the results are comparable with those of induction by intravenous oxytocin. Nevertheless, repeated doses are required and the best regimen remains to be determined. Bremme et $a l^{13}$ recently reported a series of 30 women in whom labour was induced using oral prostaglandin $\mathrm{E}_{2}$ when pregnancy was near full term. Three different dose schedules were evaluated, and they found that a dose of $1 \mathrm{mg}$ hourly will result in a stable plasma concentration with little evidence of accumulation and consequently less risk of uterine hyperstimulation.

Another new method recently developed for the introduction of prostaglandins is by intravaginal or intracervical gel.14 Incremental doses may be necessary to establish progressive labour, and a major disadvantage is that there is no means of control of the rate of absorption.

No doubt remains about the efficacy of prostaglandins in the induction of labour or therapeutic abortion, but there remain the problems associated with the incidence of doserelated side effects and with unpredictable oxytocic activity. Predicting the pharmacological effects of the agent depends especially on achieving a constant rate of absorption, and if this could be achieved for a convenient, acceptable preparation of prostaglandin its undoubted therapeutic value would be increased.

1 Beazley JM, Dewhurst CJ, Gillespie A. The induction of labour with prostaglandin $\mathrm{E}_{2}$. Fournal of Obstetrics and Gynaecology of the British Commonwealth 1970;77:193-9.

2 MacKenzie IZ, Embrey MP. Cervical ripening with intravaginal prostaglandin $\mathrm{E}_{2}$ gel. Br Med $\mathcal{F} 1977 ; \mathrm{ii}: 1381-4$.

3 Hutchon DJR, Geirsson R, Patel NB. Int $\mathcal{f}$ Gynaecol Obstet 1980;17: 604-7.

4 Southern EM. Prostaglandins: clinical applications in human reproduction. New York: Futura Publishing Co, 1972.

5 Karim SMM, Sharma SD. Termination of second trimester pregnancy with 15 methyl analogues of prostaglandins $E_{2}$ and $F_{2} \alpha$. fournal of Obstetrics and Gynaecology of the British Commonwealth 1972;79: 737-43.

6 Karim SMM, Sivasamboo R. Termination of second trimester pregnancy with intra-amniotic 15 (S) 15 methyl prostaglandin F-2alpha-a two dose schedule study. Prostaglandins 1975;9:487-94.

7 Krishna U, Ganguli AC, MandlekarAV, Purandare VN. Administration of prostaglandins by various routes for induction of abortion. Prostaglandins 1978;15:685-93. 
8 Amy JJ, Karim SMM, Sivasamboo R. Intra-amniotic administration of prostaglandin 15 (S) 15-methyl- $E_{2}$ methyl ester for termination of pregnancy. Fournal of Obstetrics and Gynaecology of the British Commonwealth 1973;80:1017-20.

9 Wiqvist N, Bygdeman $M$. Therapeutic abortion by local administration of prostaglandin. Lancet 1970 ;ii:716-7.

${ }^{10}$ Fraser IS. Uterine hypertonus after oral prostaglandin $\mathrm{E}_{2}$. Lancet 1974; ii: 162 .

${ }^{11}$ Kelly J, Flynn AM, Bertrand PV. A comparison of oral prostaglandin $\mathrm{E}_{2}$ and intravenous Syntocinon in the induction of labour. Fournal of Obstetrics and Gynaecology of the British Commonwealth 1973;80:923-6.

${ }^{12}$ Miller JF, Welply GA, Elstein M. Prostaglandin $\mathrm{E}_{2}$ tablets compared with intravenous oxytocin in induction of labour. $\mathrm{Br} \mathrm{Med} \mathcal{F} 1975$; : 14-6.

${ }^{13}$ Bremme $\mathrm{K}$, Kindahl $\mathrm{H}$, Svanborg $\mathrm{K}$. Induction of labor by oral $\mathrm{PGE}_{2}$ administration-evaluation of different dose schedules. Acta Obstet Gynecol Scand 1980;92, suppl: 5-10.

14 Williams $\mathrm{RM}$. Induction of labour with intravaginal prostaglandin $\mathrm{E}_{2}$ gel. Br 7 Clin Pract $1979 ; 33: 131-2$.

\section{Asymptomatic space- occupying lesions of the kidney}

Finding an asymptomatic space-occupying lesion within the kidney during a routine urological investigation is still a diagnostic challenge. ${ }^{1}$ Such a lesion is often discovered when investigating patients, many of them elderly, with prostatism or hypertension. The clinician has then to decide whether non-invasive techniques are sufficiently accurate to differentiate a benign cyst from a renal tumour or whether the patient should be subjected to invasive investigations, with their definite but low morbidity, or even have exploratory surgery.

Modern ultrasound equipment has made sonar an attractive diagnostic method, ${ }^{2}$ and the increasing availability of computed tomography (CT) will often provide confirmation of the diagnosis where ultrasound raises doubt about the nature of the lesion. What, therefore, are the limitations of the various diagnostic techniques? Intravenous urography itself can go further than simply showing the existence of a spaceoccupying lesion. The nephrogram phase may show the presence of a lucent defect in the suspicious area; its absence raises the chances of the presence of a renal tumour to a high level. Ultrasound can now offer the experienced clinician an $80-90 \%$ diagnostic rate, and in the elderly patient this technique may show smaller cystic lesions not producing displacement of the calix, thus helping to confirm the diagnosis. Puncture of a cyst is a valuable adjunct, which may be combined with ultrasound or conventional radiology, but its main limitation is the hazard of damaging blood vessels, especially with centrally placed cysts. A dry tap may be obtained even in experienced hands, and there is a theoretical risk of disseminating tumour cells into the needle track when the lesion is found to be a solid tumour. A successful puncture may, however, be combined with cytological and biochemical analysis of the aspirated cyst fluid, while the character of the internal surface of the cyst may be shown by injection of a contrast medium: a uniformly smooth interior is confirmation of a benign lesion. ${ }^{3}$ Very few such cysts will contain a tumour. ${ }^{4}$

Ultrasound will give a definite answer in the tumour that produces definite echoes and in the classic cyst, with a complete absence of echoes and distal enhancement. The problems arise when a few low-level echoes are present, which may be due either to technical artefacts or to a homogeneous tumour. In this minority of cases CT will usually determine whether the lesion is solid, but the limits of resolution of this technique are around $1-1.5 \mathrm{~cm}$ and it can give little help with small lesions.

Where doubt remains selective renal angiography will nearly always show a pathological circulation if the lesion is a renal tumour, even if small..$^{5}$ Arterial puncture has small but definite risks, particularly in elderly atherosclerotic patients, and on rare occasions it may fail because of arterial diseasebut in experienced hands selective renal angiography is now very safe. Even this technique sometimes leaves doubt about the diagnosis, especially with cystic renal neoplasms, when exploration becomes the final Court of Appeal. Operative exploration is, however, undoubtedly hazardous: in a series of 126 patients who underwent exploration Kropp et $a l^{6}$ reported a morbidity of $30 \%$ and two deaths.

What, then, should be the sensible policy? The nature of most asymptomatic space-occupying renal lesions may be determined by intravenous urography and ultrasound. When available, CT will help in doubtful cases when a few low-level echoes are present, and puncture of a cyst is also useful in the peripheral lesion, allowing assessment of the internal cyst wall. Angiography may then be reserved for the small or echogenic lesion and where cyst puncture fails or shows abnormalities of the cyst wall. Only in the rare instance where, despite investigation, doubt remains is exploration justifiable. Nevertheless, the combination of a space-occupying lesion with haematuria (particularly when the lower urinary tract is found to be normal) should alert the clinician to turn more readily to angiography. This pattern shifts the burden of proof so that the task is disproving the presence of a renal neoplasm rather than confirming the presence of a benign renal cyst.

${ }^{1}$ Ambrose SS, Lewis EL, O'Brien DP, Walton KN, Ross JR. Unsuspected renal tumours associated with renal cysts. $\mathcal{F}$ Urol 1977;117:704-7.

2 Barnett E, Morley P. Ultrasound in the investigation of space-occupying lesions of the urinary tract. Br $\mathcal{F}$ Radiol $1971 ; 44: 733-42$.

${ }^{3}$ Lang EK, Johnson B, Chance HL, et al. Assessment of avascular renal mass lesions: the use of nephrotomography, arteriography, cyst puncture, double contrast study and histochemical and histopathologic examination of the aspirate. South Med f $1972 ; 65: 1-10$.

${ }^{4}$ Johnson KE, Plain CL, Farcon E, Morales P. Management of intrarenal peripelvic cysts. Urology $1974 ; 4$ :514-8.

5 Thomas ML, Mayo ME. Radiology in the management of asymptomatic renal space-occupying lesions. Br Med f 1970;iii:689-91.

${ }^{6}$ Kropp KA, Grayhack JT, Wendel RM, Dahl DS. Morbidity and mortality of renal exploration for cyst. Surg Gynecol Obstet 1967;125:803-6.

\section{Blunt abdominal trauma}

Severe blunt abdominal trauma may occur on the sports field, in heavy industries such as coal mining, and in civilian violence, but in most cases it is due to a road-traffic accident. The increasing importance of the motorcar as the cause of such injuries was emphasised in the recent BMA symposium on road accidents held in Birmingham. ${ }^{1}$ With increasing congestion on the motorways the incidence and severity of the trauma show no signs of coming under control. Closed abdominal injuries are likely to affect, in decreasing order of frequency, the kidney, spleen, and liver; less often the pancreas, bladder, or intestine may be damaged. ${ }^{2}$ Often multiple organs are injured, and when there are associated injuries of chest, head, and the arms and legs mortality is likely to be high. Nicholson and Golden, ${ }^{3}$ for example, reported no fewer than eight deaths (seven with extensive intra-abdominal haemor- 